\title{
IMPLEMENTATION OF CAPACITIVE TOUCH SENSORS ON ARTWORKS FOR AUGUMENTATION OF USER EXPERIENCE OF BLIND AND VISUALLY IMPAIRED USERS
}

\author{
Marija Jevtić, Deja Muck, Helena Gabrijelčič Tomc (it) \\ University of Ljubljana, Faculty of Natural Sciences and Engineering, \\ Department of Textiles, Graphic Arts and Design, Ljubljana, Slovenia
}

\begin{abstract}
This research presents the results of the study in which the artworks are exhibited to blind and visually impaired persons and an automatic verbal tour guide with capacitive sensors is implemented. The aim of the research is the development of a prototype for audio interpretation of 3D printed artworks for enhancement of the experience of blind and visually impaired persons. The proposed solution enable the blind and visually impaired persons to touch and hear information when accessing the 3D printed object, i.e. after the approatching of the 3D object and the user's touch there is a programmed synchronised turn on of the voice explanining the set of information about the object. For each touched form (shape) of the artwork the blind and visually impaired person has a complete insight in relation with other shapes in the vicinity, and consequently the user is able to experience the whole artwork, to comprehend what it is all about, which artistic movements or age it belongs to, the handwriting of artist, and in the context of experiencing the exhibition place, the concept of the exhibition, etc. In front of each artwork there is a plate in Braille alphabet with the name of the artist, year of its creation, used technique, and the name of the gallery. Further, in the results the technology of the sensors is presented, their composition and the implementation in 3D printed objects is explained and based on a usability testing advantages and disadvantages of the presented application of capacitive sensors are critically discussed.
\end{abstract}

Key words: capacitive touch sensors, 3D printed artwork, blind and visually impared, accessibility, augumentation

\section{INTRODUCTION}

Most museums and galleries present and exhibit reproductions of sculptures, paintings and other artefacts interpreted with the languages (usually 3D tactile) that enable the accessibility of the art for blind and visually impaired persons. These models are usually hand-made by artists and thus provide artistic 3D interpretation of the original artwork. However, many 2D art works and new media products are still not available for the target groups with visual limitations. Here, some rear exceptions (museums) have to be mentioned, i.e. State Tactile Museum Omero (Ancona, Italy) or The Art Institute of Chicago (Illinois, United States of America) that implemented tactile displays dedicated to blind people. In order to increase and accelerate the "translation" process of interpretation from visual into tactile several computer aided approaches have been developed over the past few years. Recent studies suggest that only tactile interpretation with 3D models (even in the case when they optimally reproduce the original image) is not enough for a complete understanding and enjoyment of an artwork (Feucht et al, 2018). In Figure 1 computer approach is presented that aimed to facilitate experiencing an artwork. The Kinect sensor is placed at the distance of $1 \mathrm{~m}$ from tested model. The test starts with calibration of manual tracking (requested by applied method) and the registeration of a manual model on users' hands (Wang et al, 2012).

a)

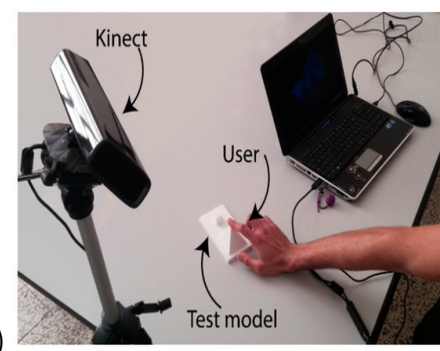

b)

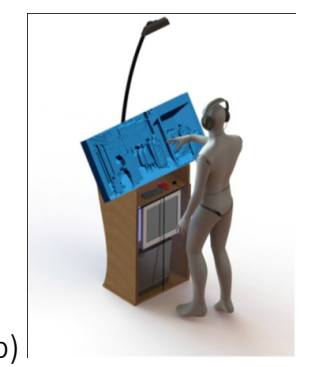

Figure 1: a) Touch identification iardware b) user in front of a model 
Blind people who understand the original artistic work are, in fact, subject to many factors (e.g. the person's sensitivity and capability, previous experience, the size and quality of the tactile model); for this reason, when the interpretation is verbal, the quality of verbal guidance is essential in order to appreciate the best possible reproduction of artistic relief of a particular image. Such verbal description is usually provided by an informed person (employees of the museum, accompanying person, etc.) that help the blind person to build a complete mental image of the tactile model. However, the presence of another person can be viewed as a limiting factor in the enjoyment of works of art, since a blind person is forced to discover through the perspective of someone else; art is a language that requires autonomy and freedom to be fully captured (Foreword et al, 2009).

In the presented research the technical part is primarily considered and, consequently, the functioning mode of a tactile transfer of voice, where capacitive sensors play an important role. The task of sensors is to collect different information regarding certain processes. These units can be used before or after the processes. Sensors detect properties that can be measured and converted into some useul form, usually into electric signals. Sensors are also named convertors. Convertor is device transforming signal of one physical size into signal of another physical size. Capacitive sensors for detection of moving are contact or non-contact devices having ability to measure precisely / detect position and / or position change of moving object. The following example in Figure 2 illustrates the installation of the capacitive sensor in the model, which there can be tested voice reproduction on.

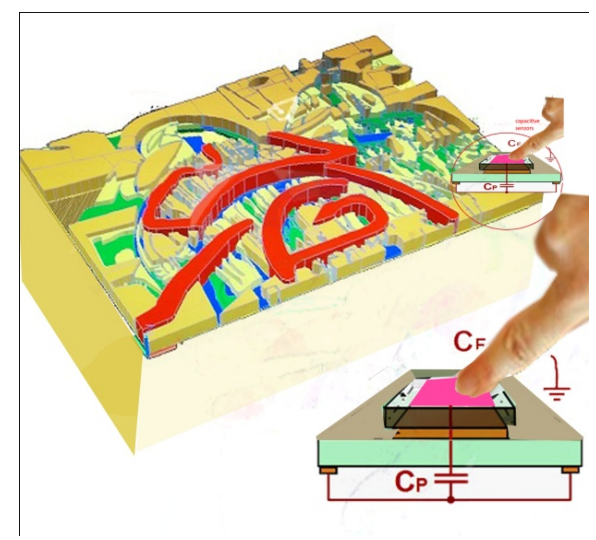

Figure 2: Instalation of the capacitive sensor in an artwork

The accessibility of the artworks should be enabled with the adequate technical equipment of the galleries. In Figure 3a the example of a blind person trying to experience the artwork is shown, on the left there is a 2D painting and on the right a 3D object (Okamoto et al, 2013).

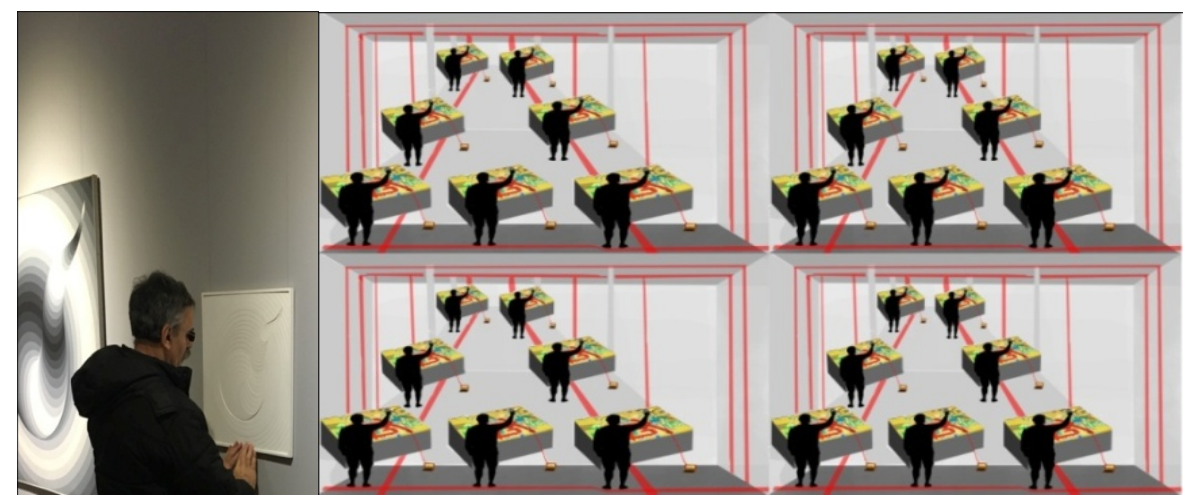

Figure 3: 3D object, 2D picture and blind person (left), people in the gallery receive information about work with the help of an automatic verbal guide (right)

The aim of the research is the development of the methodology and a prototype of a technical solution for audio interpretation of 3D printed artworks for enhancement of the experience of blind and visually impaired users. With this purpose the capacitive sensors were used and implemented in the installation of $3 \mathrm{D}$ printed objects that improved the user experience when interacting with the art work. 


\section{METODS}

In Figure 4 experimental concept is described including on one side users/participants (blind and visually impared persons) and capacitive touch sensors. When new trends in the art for the blind are introduced new frontiers are opened giving the space for the implementation of sensors, speech synthesizer, 3D printed objects etc.

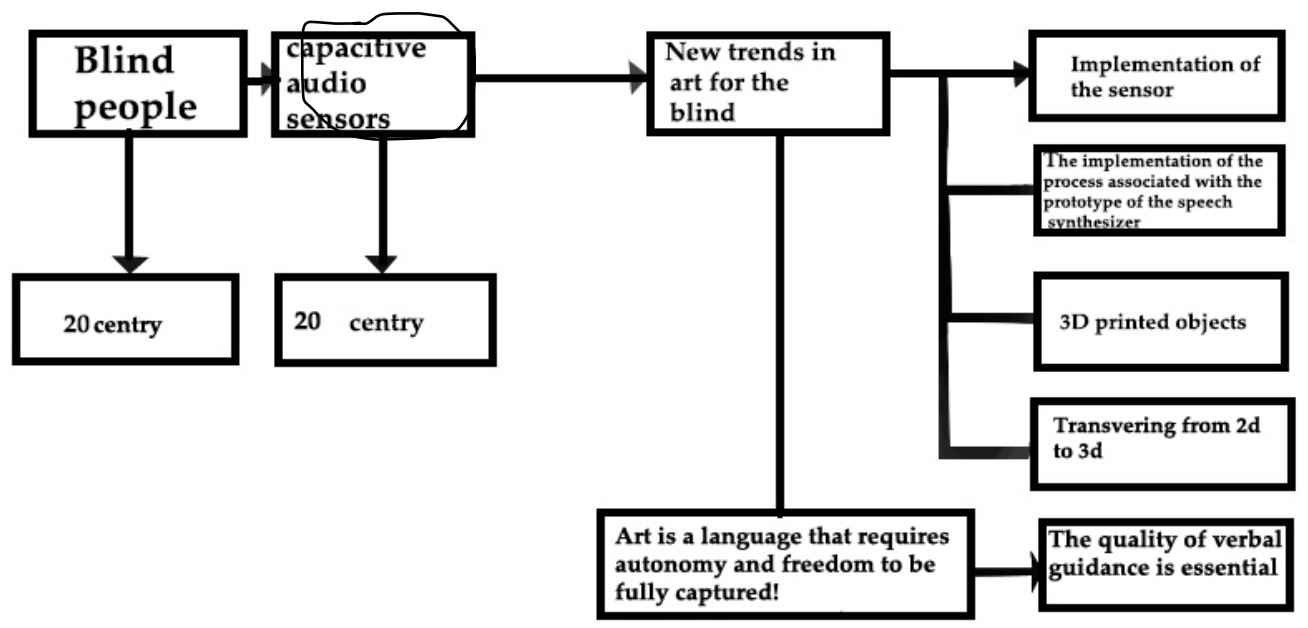

Figure 4: The schematic presentation of experimental

In the study twenty blind or visually impared persons participated. The performance of the analysis took place in the art gallery where the artworks were exhibited. Five of the respondents said that there was no need to introduce audio guidance, due to an explanation in the form of Braille beside the model. These persons were blind from the birth and have excellent knowledge of Braille alphabet. Fifteen respondents confirmed the need for the audio guidance, due to the fact that they have lost the vision later in the lives and were not blind from the birth. Consequently, they did not learn Braille alphabet and for them the verbal guidance was indispensable. After the implementation of the process associated with the prototype of the speech synthesizer and verbal guidance, the testing was performed on a target group, that discovered the disadvantages and advantages of the performance and whether the synthesizer with the capacitive sensor was sufficiently persuasive to allow the blind and the visually impaired to fully grasp the artwork. The results of the testing is presented in Table 1 and 2, where Table 2 represents the results of the exploration of capacitive sensors according to their speed, sensitivity, pass time, financial profitability, and wider use (Bert, 2018). The examples in Figure 5 show a 3D printed model and a 3D model shaped in Auto Cad with the marked locations where the capacitive sensors can be touched.

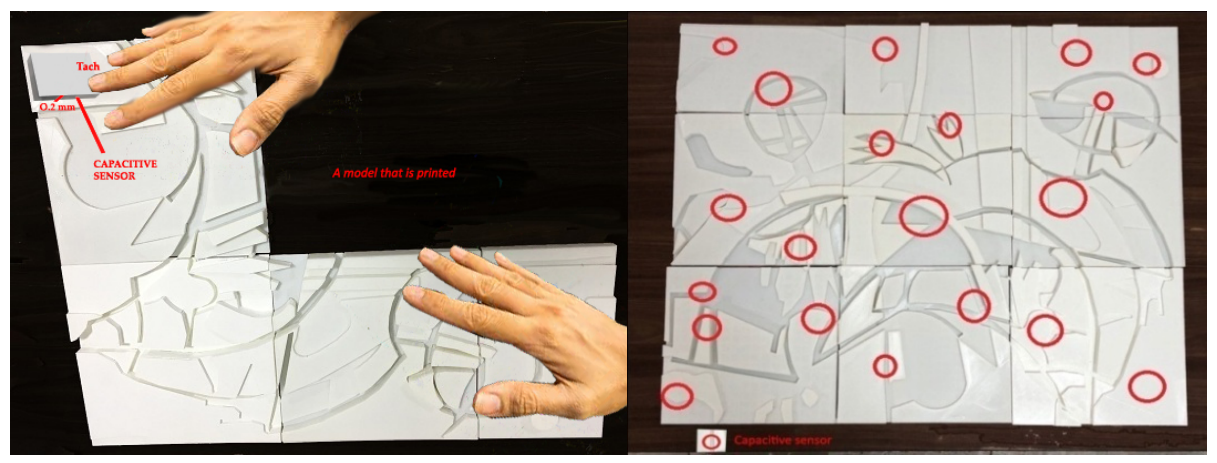

Figure 5: The appearance of a capacitive sensor (left) and 3D printed model with the locations of the capacitive sensors (right) 
In Figure 6 the functions of capacitive touch sensors and Installations of the automatic verbal guides in the gallery are presented, which enable the visitors to receive information about artworks.

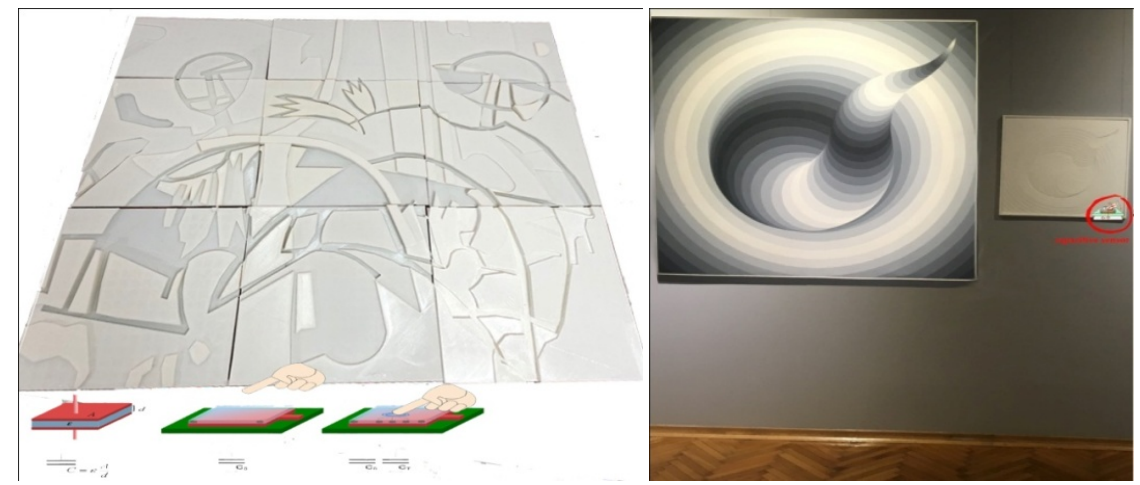

Figure 6: Functions of capacitive touch sensors (left), Installations of the automatic verbal guidesin the gallery (right)

\section{RESULTS}

The results of the research were 3D printed objects (carefully planned and prototyped with 3D modelling). 3D printed objcts were developed from the artworks and each 3D model had implemented a speech sensor, which activation was enabled with the touch of the 3D object's surface. After being entitled to approach the 3D object and to touch its surface, a voice sensor transmited audio information about the artwork, its properties, its surface and its size, what color it is, what is the texture, in which direction it extends, where the dents and bumps are, how are the edges formed and if they are smooth or sharp. In Figure 7 the activities of the participants are shematically presented.

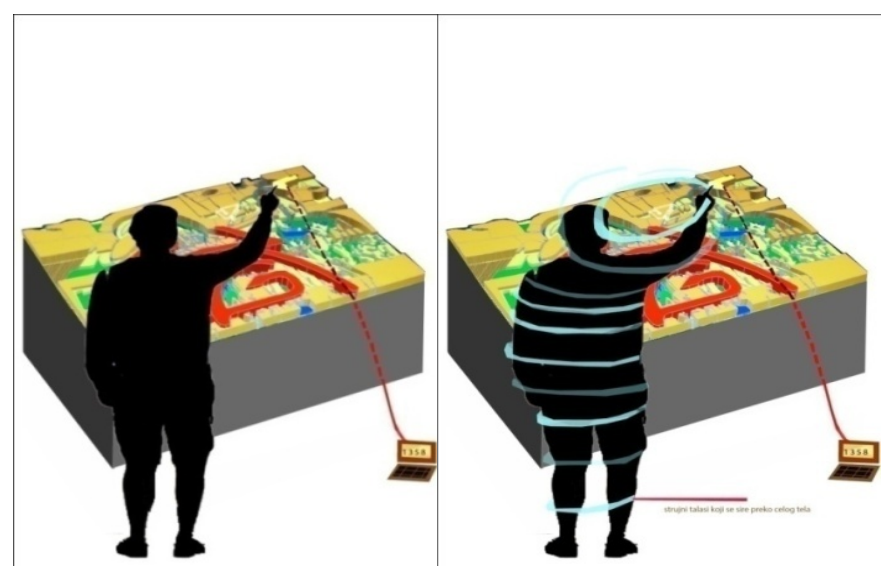

Figure 7: Participants in the research (visitors in the gallery) that through voice command and touch activities receive information about the artwork using an automatic verbal guide including capacitive sensors.

This research was conducted in order to discover if there is necessary to install capacitive sensors into printed models. Touch capacitive sensor were installed in each exhibited 3D objects allowing the visitors to activate it by moving hand over it. During the examinations each participant gave data about the age and how old he/her was when he/her lost the sight. In Table 1 the participants are presented with gender, age, time of vision los and if according to their experience they consider capacitive sensors as usefull solution or not. Based on this table, it can be concluded that majority (12) participants of both genders were able to use successfully the capacitive sensors and express the opinion that their implementation is useful. When analysing the gender of the participants, the results show that 6 women and 6 men evaluated the capacitive sensors as useful and the same gender ration was also present for the participants that were not favourable for the proposed solution. 
Table 1: Results of the participants' evaluation of the implementation of capacitive sensors in 3D printed artworks

\begin{tabular}{|c|c|c|c|c|}
\hline No. & Gender & Time of vision los & Age & $\begin{array}{c}\text { For (yes) / against } \\
\text { (no) capacitive } \\
\text { sensors }\end{array}$ \\
\hline 1 & Lady & 58 & 83 & yes \\
\hline 2 & Lady & 50 & 72 & yes \\
\hline 3 & Lady & 55 & 65 & yes \\
\hline 4 & Lady & 12 & 56 & no \\
\hline 5 & Lady & 32 & 50 & yes \\
\hline 6 & Lady & 41 & 55 & yes \\
\hline 7 & Lady & 11 & 39 & no \\
\hline 8 & Lady & 19 & 47 & no \\
\hline 9 & Lady & 22 & 68 & yes \\
\hline 10 & Lady & 42 & 59 & yes \\
\hline 11 & Man & 0 & 44 & no \\
\hline 12 & Man & 44 & 75 & yes \\
\hline 13 & Man & 26 & 45 & yes \\
\hline 14 & Man & 24 & 65 & no \\
\hline 15 & Man & 43 & 50 & yes \\
\hline 16 & Man & 7 & 41 & no \\
\hline 17 & Man & 36 & 67 & yes \\
\hline 18 & Man & 15 & 38 & no \\
\hline 19 & Man & 33 & 57 & yes \\
\hline 20 & Man & 50 & 84 & yes \\
\hline
\end{tabular}

Further, usability testing was performed with a questionnaire about the capacitive sensors' sensitivity, speed and time of turning on the audio guide, about financial effects and wider use (table 2). Here, 18 participants were questioned and their evaluation about the sensors properties were recorded. In Table 2, we can conclude that capacitive sensor developed for the analysed 3D models were not evaluated as useful for wider use. In our opinion this was due to the plastic materials, which the sensors were built from. The participants responded to financial profit with great portion of dislikes, while they have better evaluated pass time, speed; and the best evaluated was sensitivity.

Table 2: Evaluation of the properties of capacitive sesors

\begin{tabular}{|c|c|c|c|c|c|}
\hline Participants & Sensitivity & Spid & Release time & Financial profitability & Wider use \\
\hline 1 & Good & Good & Good & Good & Medium \\
\hline 2 & Good & Good & Medium & Medium & Medium \\
\hline 3 & Good & Medium & Good & Medium & Good \\
\hline 4 & Good & Medium & Good & Good & $\mathrm{Bad}$ \\
\hline 5 & Good & Good & Medium & Medium & Medium \\
\hline 6 & Good & Medium & Good & Good & Good \\
\hline 7 & Good & Good & Medium & Medium & Medium \\
\hline 8 & Medium & Good & Good & Medium & Bad \\
\hline 9 & Good & Good & Medium & Medium & Medium \\
\hline 10 & Good & Medium & Good & Medium & Medium \\
\hline 11 & Good & Good & Medium & Good & Bad \\
\hline 12 & Good & Good & Medium & Medium & Bad \\
\hline 13 & Medium & Good & Good & Good & Bad \\
\hline 14 & Good & Medium & Good & Good & Medium \\
\hline 15 & Good & Good & Good & Medium & Bad \\
\hline 16 & Good & Good & Mediium & Good & Bad \\
\hline 17 & Good & Medium & Good & Good & Medium \\
\hline 18 & Good & Good & Medium & Medium & Bad \\
\hline
\end{tabular}




\section{CONCLUSIONS}

In the paper the successful collaboration of the art and the technology is presented. Capacitive touch sensors were implemented in 3D models done from the artists in order to enable the blind and visually impared persons more comprehensive experience of the art. In further researches, the technology of capacitive audio sensors is going to be improved and new printed artworks are going to be tested. Besides, for the valuable testing of usability and user experience the performance and issue based matrices are going to be performed with additional tools and analysis.

\section{REFERENCES}

[1] Bert T.: "Sensitivity to Social Contingency in Adults with High-Functioning Autism during ComputerMediated Embodied Interaction", Plan de EstudiosCombinadosenMedicina, PhD thesis, Facultad de Medicina, Universidad Nacional Autónoma de México, Mexico City, Mexico, 2018.

[2] Feucht, F.C.; Holmgren, C.R.: "Developing Tactile Maps for Students with Visual Impairments: A Case Study for Customizing Accommodations", Journal of Visual Impairment \& Blindness 112(2), 143-155, 2018.

[3] Foreword., Catherine K.: "Groundwork for a History of Blindness", (French University, 2009).

[4] Okamoto, T., Mitsui, C., Yamagishi, M., Nakahara, K., Soeda, J., Hirose, Y., Miwa, K., Yamano, A., Matsusha, T., Uemura, T., Takeya, J.: "V-shaped organic semiconductor with solution processability, high mobility, and high thermal durability", Advanced Materials 25(44), 2013, 6392 - 6397. doi: 10.1002/adma.201302086.

[5] Wang, M.,Chang, J., Jens, K., Zhang, J.J.:"A Framework for Digital Sunken Relief Generation Based on 3D Geometric Models" The Media School, Bournemouth University, Poole, Germany. The Visual Computer, 28(11), 1127-1137, 2012. doi: 10.1007/s00371-011-0663-y.

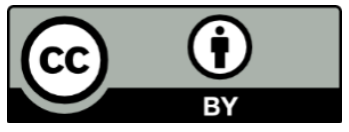

(C) 2018 Authors. Published by the University of Novi Sad, Faculty of Technical Sciences, Department of Graphic Engineering and Design. This article is an open access article distributed under the terms and conditions of the Creative Commons Attribution license 3.0 Serbia

(http://creativecommons.org/licenses/by/3.0/rs/). 